\title{
Leonarda Rivera. Don Juan y la filosofía. México, Siglo XXI, 2019
}

\author{
Tatiana Aguilar-Álvarez Bay \\ Universidad Nacional Autónoma de México \\ Instituto de Investigaciones Filológicas \\ tatiana.bay@gmail.com
}

\section{Nuevos enfoques para un mito clásico: Don Juan y la filosofía}

Si me preguntaran por la palabra que asocio de inmediato con el libro Don Juan y la filosofía, no dudaría en responder con el calificativo fascinante. Esto, por diversos motivos que iré comentando a lo largo de mi exposición. El término me recuerda la primera vez que escuché a Leonarda Rivera hablar del Tenorio. Fue hace algunos años, en octubre de 2016, en un concurrido local de San Cristóbal de Las Casas, donde bebíamos chocolate con un grupo de amigos. Acudimos a esa ciudad como participantes del Decimoctavo Congreso Internacional de Filosofía; la neblina empañaba los cristales y se volvía necesario hablar alto por el ruido de la conversación en las mesas y por la constante entrada y salida del tropel de filósofos que abarrotaba las calles. Sentada junto a mí, Leonarda comenzó a platicarme de su proyecto de investigación con ese brillo que aparece en sus ojos cuando habla de don Juan. Recuerdo que mencionó el libro Mitos del individualismo moderno, sobre Fausto, don Quijote, don Juan y Robinson Crusoe, en el cual se presenta un marco útil para el tipo de cuestiones que a ella le interesan, en particular para aproximarse al Tenorio, esa escurridiza sombra que viene persiguiendo desde hace tiempo. Mientras la tarde transcurría, se alzaba ante mí don Juan, cuya silueta intrigante y única destellaba en la conversación. En las muchas otras ocasiones en que hemos retomado el tema, vuelvo a observar la inquietud de la autora del libro por don Juan, un personaje que en manuales y trabajos escolares aparece algo empolvado, desprovisto de la fuerza por la que desafía las leyes humanas y divinas. Como una espada sin filo. Como un farsante que se pavonea de las conquistas que va sumando. Como un bulto bajo el peso del tiempo. En cambio, en Don Juan y la Filosofía se argumentan con sutileza cuestiones filosóficas, distintas según el autor y la época, que convergen en este personaje; se le restituyen a don Juan: el filo de la rebeldía; el frenesí erótico, contrario al aviso lúgubre de la fugacidad; la rapidez del espadachín, que apuesta incluso cuando está al borde de la muerte. 
Si se mira con atención, la palabra fascinante corresponde cabalmente al personaje, cuyas diversas facetas bien merecen este calificativo que, según el Diccionario de la Lengua Española hace referencia a la cualidad de "atraer irresistiblemente”. ¿Hay mejor manera de referirse al seductor por antonomasia? La amplia documentación y el rigor, sumados a la emocionada pesquisa personal, explican la amenidad e interés del libro, en el cual la filosofía y la literatura, el ceñido andamiaje intelectual y el estilo, se conjuntan de forma ejemplar. Aun cuando la cita sea algo extensa, doy aquí un ejemplo de esta prosa que combina la fluidez con la precisión. Se trata de un fragmento sobre el poder de seducción, en el cual se explican las condiciones que permiten a don Juan instalarse en la despreocupación y conservar la ligereza:

Este poderío seductor solo es explicable por aquello de lo que don Juan carece. Y esa falta es justamente [de] las potencias centrales del alma; la experiencia fijada por la reflexión, la memoria, el darse cuenta del propio discurrir del tiempo. Sin experiencia, los momentos de la vida de don Juan son como instantes aislados, sin trabazón y sin continuidad. Sin memoria, las conquistas tienen la extraña condición de ser diferentes y de ser la misma. Su paso por la tierra es ligero porque carece de todo aquello que da consistencia a una vida, no crea costumbres, recuerdos, compromisos. Todos los días son para él un estreno y una aventura, sin heridas ni pesadumbres (36).

Con su habitual agudeza, Sergio Pitol había señalado este rasgo "incomprensible" de don Juan: "Por eso en el fondo nadie llegará a comprender a Don Giovanni. Don Juan carece de pasado y no intuye ni le interesa el futuro" (Pitol 2006: 75).

Una vez comentado el tono general del ensayo, me detengo de forma breve en su contenido. Para empezar, destaca la estructura; el libro consta de nueve capítulos de distinto tipo. Por un lado, cinco ensayos sobre aspectos de don Juan, como la libertad, la vertiente romántica del personaje, la melancolía - entre otros-. De otro, cuatro estudios sobre las interpretaciones del Tenorio de Kierkegaard, la Generación del 98, María Zambrano y Eugenio Trías.

No quiero explayarme sobre todos los capítulos del libro; a modo de muestra, comento brevemente el primero y el último, en los cuales se reflexiona sobre don Juan en el arte barroco español, del cual es emblema el personaje creado por Tirso de Molina. Cabe apuntar que, por la complejidad y la pertinacia de su conducta, la figura barroca parece ser de mayor interés que el don Juan de Zorrilla, quien acaba por redimirse a través del amor.

El don Juan de Tirso encarna los conflictos de su época, como se expone en "Don Juan y la paradoja de la libertad", en el cual el pleno ejercicio del libre albedrío, entendido como afirmación del goce efímero, se contrapone a la idea de gracia luterana. A estos dos esquemas corresponden don Juan y Fausto, figuras 
que se comparan a lo largo del libro, a modo de contrapunto. El contrastar distintos personajes permite precisar los rasgos de cada uno de ellos. Es el caso de la relación de don Juan y Fausto con el Demonio; el primero no necesita un agente externo que lo empuje a la condenación, mientras que el segundo recurre al célebre pacto con Mefistófeles. El contraste entre don Juan y don Quijote se produce, por ejemplo, en la conducta hacia la mujer, que de aquel solo recibe injurias y de este la más refinada cortesía. El capítulo sobre la melancolía en don Juan también nos introduce en el universo barroco, ya que dicha afección desequilibra a personajes que, como el propio Tenorio, traspasan prohibiciones y límites. Se entiende entonces que, en la Contrarreforma, don Juan haya podido funcionar como ejemplo del castigo que reciben quienes desafían los mandatos divinos. A lo anterior se suma la soledad infranqueable del personaje, debida a la incapacidad para reconocer al otro. De este modo, según las épocas y los autores, don Juan no solo adopta distintos ropajes, sino diferentes conflictos ligados al surgimiento de la modernidad.

El libro concluye con un apartado de cuatro apéndices sobre elementos teóricos que, en caso de intercalarse en la exposición, podrían haber sido distractores, lo que constituye un gesto de cortesía con el lector que transita así con deleite por las páginas de la primera parte, a la vez que puede consultar el compendio teórico del final. Con el espíritu lúdico y digresivo propio del ensayo, se incluyen además reproducciones de Goya y De- lacroix, entre otros, como complemento del ensayo "Cor ne edito: sobre la irrepresentabilidad de don Juan en la pintura"; el cuento "Don Juan", de Hoffmann, y como colofón el ensayo: "Don Juan y el romanticismo". Estamos ante un atractivo mosaico que permite pasear la mirada por épocas y por interpretaciones de una figura cuyos orígenes todavía no han sido del todo establecidos. Sin embargo, la multiplicidad de facetas resulta compatible con la unidad que se sustenta en una adecuada metodología.

El enfoque unitario proviene de un par de nociones filosóficas: el "personaje conceptual" y la "categoría del lugar". En efecto, estos son los ejes de El Quijote y la filosofía, como se señala a propósito de la tesis de Unamuno acerca de la presencia ineludible de la literatura en la filosofía española: “[...] una tradición filosófica que tiene en su interior una serie de figuras literarias que devienen personajes conceptuales; son estos los que en este libro aparecen bajo el nombre de lugares o topoi" (122). La noción de personaje conceptual se expone principalmente en el ensayo sobre Kierkegaard; mientras que el último apéndice se dedica a "La categoría de 'el lugar' (topos) en María Zambrano", notable por su complejidad y rigor. La figura de don Juan ha sido objeto de muy numerosos estudios, efectuados desde diversos métodos, como podría ser la Tematología, sobre la que también se ofrece un oportuno apéndice. Ante la proliferación de investigaciones de corte literario, uno de los principales méritos de Don Juan y la filosofía consiste en que adopta un enfoque que abre nuevas 
discusiones acerca de este motivo recurrente en el arte y la literatura. Junto con la noción de "personaje conceptual", tomada de Deleuze y Guattari, emplea en el análisis el concepto de 'lugar', también en acepción filosófica; este término remite a la vertiente ontológica de la propuesta sobre el arte de María Zambrano, ya que el 'lugar' se entiende como 'abertura', a través de la cual emergen los sueños y fantasmas de un pueblo. Por ello, las aproximaciones de la filósofa española a pintores y poetas se desmarcan de la crítica especializada e incluso de la estética. A la luz de un lugar, como puede ser don Juan, se avanza en la comprensión del ser; en este caso, de algunos aspectos de la realidad española.

Con estas dos herramientas, la del personaje conceptual y la del lugar, se desarrolla de forma unitaria la cuestión de don Juan, sin menoscabo de la diversidad del personaje. El análisis no se reduce a un juego de semejanzas y diferencias, sino que en las diversas aristas se insiste en determinados puntos, como la seducción, la libertad, el deseo. Se configura así una espiral mediante la cual se ahonda en las capas superpuestas en una figura que parece desdoblarse, pero sin agotarse en ninguna de estas sucesivas interpretaciones. Así, en una exacta nota se distingue la idea hegeliana sobre el concepto que abarca el contenido del arte, de la categoría del lugar en Zambrano: “[...] los lugares siempre pueden ser leídos de otro modo; leídos y recreados. De ahí que haya un principio de variación que les es inherente. Los topoi se recrean, y en cada movimiento que ejecutan nos dejan ver un fragmento de la comprensión del ser" (n. 7, 131). Vuelta tras vuelta, don Juan en Kierkegaard y Mozart; don Juan romántico, don Juan y la Generación del 98, y así sucesivamente, el legendario seductor va ganando en complejidad, escapa de la visión acostumbrada y se muestra, efectivamente, cada vez más fascinante.

Como expone Leonarda Rivera, para el filósofo danés el don Juan de Mozart y Da Ponte encarna el ímpetu de la pasión, la fuerza dionisiaca de la naturaleza, la tierra que retumba en la risa báquica, un estado elemental que se expresa musicalmente, ya que el lenguaje supone reflexión y, en esta medida, reduce la espontaneidad. Don Juan parece ser entonces un impulso descontrolado que se identifica con el ciclo ciego de creación y destrucción. Desde esta perspectiva, el Tenorio pertenece al dominio de lo demoniaco: "El reino de don Juan, su hábitat natural, es ese reino de la impunidad de las fuerzas de la naturaleza, ámbito por excelencia de la inmanencia estética y lejos de las categorías éticas; don Juan es una potencia, no un hombre, una potencia que resuena vibrante y seductora en la obertura de Mozart" (34).

Llegados a este punto, más que seguir comentando el libro, se antoja lanzar algunas preguntas. ¿La impersonalidad de don Juan, en tanto que representa la fuerza telúrica, supone cierta inocencia? ¿A la infinitud del deseo, acaso podría corresponder el gesto inocente por carecer de reflexión? La posible conjunción de opuestos constituye una de las líneas que, a mi juicio, podrían explorarse en ese taller sobre el Tenorio que Leonarda 
mantiene siempre actualizado. Asimismo, me gustaría saber si en este personaje cabe la sonrisa, tan celebrada en el Quijote, o solo le concierne la carcajada burlona. ¿La imposibilidad de la sonrisa no será el infierno al que sin remedio desciende el Tenorio? Si él carece de contacto con el otro, ¿cómo se explica el encanto que despliega para empatizar con las mujeres? Entre acechos y persecuciones, escondites y huidas, don Juan siempre parece tener prisa, no puede evadirse del ritmo frenético impuesto por las sucesivas conquistas. Este correr indefinido, sin tregua, es otra de sus características como emblema de la modernidad, ¿constituye la prisa una variante del infierno? El vértigo, la adrenalina, más que el erotismo, podría ser el impulso fundamental del seductor, como en un deporte de alto riesgo: "don Juan disfruta de la noche, del frío, de la adrenalina que provoca el mirarse cara a cara con la muerte" (19). También queda pendiente saber si el aspecto escénico de don Juan, al menos en la mayoría de las versiones, se relaciona con lo que este representa: ¿corresponde a la seducción un cierto fingimiento inherente al teatro?

Don Juan y la filosofía da prueba de la sólida formación y amplia cultura de la autora, como se pone de manifiesto, por ejemplo, en las pertinentes notas a pie de página que incrementan el interés de la lectura; al reanimar a una figura clave de nuestra tradición, se nos da mucho que pensar, ya que, en este libro don Juan se incorpora y vuelve a cuestionarnos.

Para terminar, no me queda más que aplaudir que el libro haya sido galardonado con el Decimosexto Premio Internacional de Ensayo que otorgan Siglo XXI Editores, La Universidad Autónoma de Sinaloa y El Colegio de Sinaloa.

\section{Bibliografía}

Pitol, Sergio (2006). El mago de Viena. Bogotá, Fondo de Cultura Económica.

\section{Tatiana Aguilar-Álvarez Bay}

Doctora en Letras Hispánicas por El Colegio de México. Investigadora del Centro de Estudios Literarios del Instituto de Investigaciones Filológicas de la UNAM, en cuya Facultad de Filosofía y Letras es también docente. Forma parte del SNI (nivel 1). Ha publicado el libro La verdad poética en José Ángel Valente (1955-1966) (El Colegio de México, 2011), así como diversos estudios sobre su área de especialidad. Entre sus intereses están la poesía y pensamiento españoles de la primera mitad del siglo xx, la literatura del exilio republicano en México y la difusión cultural. 